\title{
Clinical approach to burst-suppression pattern in an intensive care unit: basic and updates
}

\author{
Jie Pan MD, PhD, Amputch Karukote MD, Eri Shoji MD
}

\begin{abstract}
A burst-suppression pattern is an electroencephalographic pattern characterized by a quasi-periodic high amplitude "burst" alternating with periods of low or flatline "suppression." Recognizing and understanding this pattern is helpful for clinical management in intensive care units. Pathological burst-suppression is commonly seen in post cardiac arrest comatose patients. It can also be induced by anesthetics or hypothermia. A burst-suppression pattern in anoxic brain injury generally predicts a poor prognosis; however, exceptions do occur. Inducing burstsuppression by general anesthetics can be used to abort super-refractory status epilepticus. This article will discuss this unique EEG pattern, including basic mechanisms, related clinical conditions, and recent research updates.
\end{abstract}

Keywords: EEG, burst-suppression, anoxic encephalopathy

\section{INTRODUCTION}

A burst-suppression pattern (BSP) is a unique electroencephalography pattern commonly encountered in intensive care units. The BSP occurs in the context of diffuse cerebral dysfunction with coma and indicates a clinical severity that is greater than generalized slowing but is less severe than electrocerebral inactivity. It is typically associated with a comatose state secondary to several pathophysiological etiologies, including anoxic brain injury, induced hypothermia, end stage status epilepticus, severe epileptic encephalopathies of infancy and anesthesia. The BSP was first noticed and described in the 1930-1940s; however, the mechanism and clinical significance still remain unclear. The purpose of this article is to explain this EEG pattern by discussing its recognition, mechanism(s), and related clinical conditions. Understanding

Corresponding author: Jie Pan

Contact Information: Jie.Pan@ttuhsc.edu

DOI: 10.12746/swrccc.v8i36.761 this EEG pattern is important for both neurologists and critical care specialists.

\section{DESCRIPTION AND DISTINGUISHING FEATURES}

The BSP is an electroencephalography pattern consisting of a quasi-periodic high amplitude "burst" alternating with periods of low or absent activity "suppression." This pattern is unique due to the abrupt change of amplitude between burst and suppression periods. ${ }^{1,2}$

\section{Amplitudes}

The amplitude of burst usually can vary from $20 \mu \mathrm{V}$ to $100 \mu \mathrm{V}$ while occasionally being out of this range. The amplitude of suppression is within the range from electrocerebral inactivity to $50 \mu \mathrm{V}$ but is commonly less than $10 \mu \mathrm{V}$.

\section{Duration}

A BSP is considered when more than $50 \%$ of the recording consists of suppression. Bursts are defined as waveforms lasting more than 0.5 seconds and 
having at least 4 phases (i.e., crosses the baseline at least 3 times).

\section{EEG DIFFERENTIATION WITH GENERALIZED PERIODIC DISCHARGE}

Generalized periodic discharges (GPDs) are generalized, synchronized discharges that include spikes and sharps that recur at certain intervals. Some of the clinical conditions overlap with BSP thus making recognition of this pattern essential since it can change clinical management. Generalized periodic discharge pattern can occur in various pathological conditions, including anoxic encephalopathy, severe toxic-metabolic encephalopathy, hypothermia, non-convulsive status epilepticus, and infection, e.g., subacute sclerosing panencephalopathy. ${ }^{3}$ According to American Clinical Neurophysiology Society terminology, discharges in GPDs are defined as waveforms with no more than 3 phases or any waveform lasting 0.5 seconds or less, regardless of number of phases. This is different from bursts in the BSP. ${ }^{4}$ Generally, GPD waveforms are briefer and more consistent in morphology across recurrences than the BSP.

\section{Physiology and mechanism of BURST-SUPPRESSION}

Studies have suggested that BSP is related to cortical hyperexcitability and has wide synchronization over the whole neocortex. ${ }^{5}$ Recent studies with the use of fMRI indicated correlation of cortical and subcortical region during burst-suppression. ${ }^{6}$ Neurophysiological mechanisms are complex, including NMDA receptors, gap junction transmission, extracellular $\mathrm{Ca}^{++}$concentration, ATP deficiency, and selective neuronal death. ${ }^{7,8}$

During anesthesia, bursts, or breakthrough EEG activity, are caused by intact glutamate-mediated excitatory input of the neocortex, while cortical activity is suppressed via GABAergic mechanisms. Bursts are followed by a period of suppression, or a post-burst refractory period, by intrinsic inhibitory currents related to depleted extracellular calcium concentrations. ${ }^{8,9}$

In vivo studies have suggested that burstsuppression is a state of cortical hyperexcitability.
Increased extracellular calcium concentrations transiently enhance cortical synaptic processes, leading to bursts. Depletion of calcium contributes to the reduced spontaneous firing of neurons thus leading to periods of suppression. One hypothesis indicated that BSP may reflect an intrinsic rescue mechanism for saving neural cells from death in "hostile" CNS disorders, such as anoxic injury ${ }^{10}$

\section{Clinical significance}

The BSP can be physiological, such as during early development (premature brain) or pathological, such as post cardiac arrest anoxic brain injury and severe epileptic encephalopathies of infancy (Ohtahara syndrome). Also, it can be induced by anesthetics ${ }^{11}$ or hypothermia. ${ }^{12}$

\section{BSP AFTER CARDIAC-ARREST}

The BSP is typically seen in comatose patients with diffuse cerebral dysfunction in anoxic brain injury/ post-cardiac arrest. It is usually considered a malignant EEG pattern with strong association with a poor prognosis. ${ }^{13,14}$ Other unfavorable EEG patterns include iso-electric (flatline) and low-voltage $(<20 \mu \mathrm{V})$.

However, recent data revealed that specificity of a BSP for a poor prognosis, especially within 24 hours of cardiac arrest, is less than $100 \%$. In a prospective cohort study, 60 patients underwent hypothermia protocol, and BSP after 24 hours was indicative for poor prognosis with specificity of $96 \% .^{15}$ Another study revealed poor neurological outcomes with specificity of $83 \%, 90.3 \%, 100 \%$, and $100 \%$ at 12 hours, 24 hours, 48 hours, and 72 hours post-cardiac arrest, respectively. ${ }^{16}$ Moreover, in one study, 3 patients with initial BSP had favorable outcomes after more than 2 weeks of post-anoxic coma. ${ }^{17}$ Thus more studies are needed regarding the characteristic and predictive value of this EEG pattern.

The general principle is that longer suppression is associated with poorer outcomes in post-anoxic coma. With the worsening of comatose state, BSP will evolve into suppressed EEG interrupting continuous slow waves and the suppression periods will become 
Table 1. Anesthetics Used to Induce BSP for Super-refractory Status Epilepticus

\begin{tabular}{|l|l|l|l|l|}
\hline Anesthetics & Mechanism & Dosing & Pros & Cons \\
\hline Propofol & GABA $_{\mathrm{A}}$ agonist & $\begin{array}{l}\text { Initial bolus: } 2-3 \mathrm{mg} / \mathrm{kg}, \\
\text { Maintenance: } 1-19 \mathrm{mg} / \mathrm{kg} / \mathrm{h} .\end{array}$ & $\begin{array}{l}\text { Shorter recovery time; } \\
\text { Shorter ventilator, ICU, } \\
\text { and hospital stay }\end{array}$ & $\begin{array}{l}\text { Relapses of seizure; } \\
\text { Hypotension; } \\
\text { Propofol infusion syndrome }\end{array}$ \\
\hline Thiopental & GABA $_{\mathrm{A}}$ agonist & $\begin{array}{l}\text { Induce with bolus: } 5 \mathrm{mg} / \mathrm{kg}, \\
\text { then bolus: } 1 \mathrm{mg} / \mathrm{kg} \text { every } \\
3-5 \text { min until BS achieved. } \\
\text { Maintenance: } 5 \mathrm{mg} / \mathrm{kg} / \mathrm{h} \\
\text { and titrate. Median infusion } \\
\text { rate is } 7 \mathrm{mg} / \mathrm{kg} / \mathrm{h}\end{array}$ & $\begin{array}{l}\text { Lower frequency of } \\
\text { short-term treatment } \\
\text { failure; } \\
\text { Reduced intracranial } \\
\text { pressure }\end{array}$ & $\begin{array}{l}\text { Longer recovery time, } \\
\text { Longer ICU and hospital stay; } \\
\text { Increased risk of infection; } \\
\text { Hypotension(worse than } \\
\text { propofol and midazolam) }\end{array}$ \\
\hline Midazolam & $\begin{array}{l}\text { Binds to GABA } \\
\text { benzodiazepine } \\
\text { receptor }\end{array}$ & $\begin{array}{l}\text { Bolus: } 0.15-0.5 \mathrm{mg} / \mathrm{kg}, \\
\text { Maintenance: } 0.15-0.5 \mathrm{mg} / \mathrm{kg}\end{array}$ & $\begin{array}{l}\text { Better hemodynamic } \\
\text { stability }\end{array}$ & $\begin{array}{l}\text { Less treatment response; } \\
\text { Difficult to achieve BS }\end{array}$ \\
\hline
\end{tabular}

BS-burst suppression.

longer, which eventually become non-reactivity interrupted with scattered bursts.

Burst-suppression with identical bursts is a recent concept that is exclusively observed in patients with post-cardiac arrest anoxic brain injury. One study found $20 \%$ of 101 patients with post-cardiac arrest coma showing identical bursts between 12 to 36 hours after arrest. One-hundred percent with this type of EEG versus $36 \%$ with BSP but not identical bursts had poor neurological outcomes. Also, this distinctive pattern is not observed in other pathological etiologies or anesthesia-induced burst-suppression. ${ }^{18}$ Another recent study confirmed similar findings that identical bursts are associated with poor neurological outcomes with $100 \%$ specificity. ${ }^{19}$ These recent studies suggest that identical burst patterns likely have higher specificity for predicting a poor prognosis than BSP in general.

\section{BURST-SUPPRESSION PATTERN INDUCED BY GENERAL ANESTHETICS}

ABSP indicates severe reduction in neuronal activity and metabolic rate, ${ }^{20}$ achieved at generally very deep levels of anesthesia. ${ }^{11,21,22}$ Anesthetic-induced BSPs are hypothesized to be a result of hyperexcitable intrinsic neocortex activity generated by decreased inhibition. Bispectral Index Numbers range from $7 \pm 5$,
$14 \pm 3$, and $37 \pm 12$, when the EEG showed $\leq 2,3-5$, and $\geq 6$ bursts/min, respectively. ${ }^{23}$

Pharmacological burst-suppression may provide neuroprotection in intractable epilepsy. In refractory status epilepticus, continuous intravenous anesthetics are titrated to abolish all clinical and electrographic epileptic activity to the dosage necessary to achieve BSP on the EEG. ${ }^{24}$

Although no randomized controlled trials have been conducted, the most commonly used anesthetics in refractory status epilepticus treatment include barbiturates (pentobarbital, ${ }^{25,26}$ methohexital, ${ }^{27}$ sodium thiopental ${ }^{28}$ ), propofol, and midazolam. These anesthetics exert their sedative effects chiefly through activation of the $\operatorname{GABA}(\mathrm{A})$ receptor. ${ }^{29}$ Gaseous anesthetics, including sevoflurane, ${ }^{30}$ isoflurane,$^{31}$ and desflurane, have also been noted to produce BSP, yet therapeutic usage for status epilepticus is discouraged due to its severe side effect profile (Table 1). ${ }^{29}$ Continuous EEG is essential for monitoring the response to the anesthetics and during the tapering. ${ }^{32,33}$

\section{Conclusions}

A BSP can be induced by anesthetics and hypothermia. Anesthetics can be used to induce burstsuppression in the treatment of super-refractory status 
epilepticus. When it occurs after cardiac arrest, the BSP predicts a poor prognosis. Recognizing this EEG pattern will help guide clinical management and predict prognosis.

Article citation: Pan J, Karukote A, Shoji E. Clinical approach to burst-suppression pattern in an intensive care unit: basic and updates. The Southwest Respiratory and Critical Care Chronicles 2020;8(36):61-65

From: Department of Neurology, Texas Tech University Health Sciences Center, Lubbock, Texas

Submitted: $6 / 4 / 2020$

Accepted: $10 / 3 / 2020$

Reviewer: Jannatul Ferdous MD

Conflicts of interest: none

This work is licensed under a Creative Commons

Attribution-ShareAlike 4.0 International License.

\section{REFERENCES}

1. Marcuse LV, Fields, MC, Yoo J. Rowan's Primer of EEG, second edition. Elsevier 2016; p.165.

2. Stern J. Atlas of EEG patterns. Lippincott Williams \& Wilkins 2013; p.151-52.

3. Sully KE, Husain AM. Generalized periodic discharges: a topical review. J Clin Neurophysiol 2018;35(3):199-207.

4. Hirsch LJ, LaRoche SM, Gaspard N, et al. American Clinical Neurophysiology Society's Standardized Critical Care EEG Terminology: 2012 version. J Clin Neurophysiol 2013; 30(1):1-27.

5. Amzica F. Basic physiology of burst-suppression. Epilepsia 2009;50 Suppl 12:38-9.

6. Liu X, Zhu XH, Zhang Y, et al. Neural origin of spontaneous hemodynamic fluctuations in rats under burst-suppression anesthesia condition. Cereb Cortex 2011;21(2):374-84.

7. Kroeger D, Amzica F. Hypersensitivity of the anesthesia-induced comatose brain. J Neurosci 2007;27(39):10597-607.

8. Amzica F. What does burst suppression really mean? Epilepsy Behav 2015;49:234-7.

9. Lukatch HS, Kiddoo CE, and Maciver MB. Anestheticinduced burst suppression EEG activity requires glutamatemediated excitatory synaptic transmission. Cereb Cortex 2005; 15(9):1322-31.

10. Ching S, Purdon PL, Vijayan S, et al. A neurophysiologicalmetabolic model for burst suppression. Proc Natl Acad Sci U S A 2012;109(8):3095-100.

11. Liley DT, Walsh M. The mesoscopic modeling of burst suppression during anesthesia. Front Comput Neurosci 2013;7:46.
12. Westover MB, Ching S, Kumaraswamy VM, et al. The human burst suppression electroencephalogram of deep hypothermia. Clin Neurophysiol 2015;126(10):1901-1914.

13. Amorim E, Rittenberger JC, Baldwin ME, et al. Malignant EEG patterns in cardiac arrest patients treated with targeted temperature management who survive to hospital discharge. Resuscitation 2015;90:127-32.

14. Hofmeijer J, van Putten MJ. EEG in postanoxic coma: Prognostic and diagnostic value. Clin Neurophysiol 2016;127(4): 2047-55.

15. Cloostermans MC, van Meulen FB, Eertman CJ, et al. Continuous electroencephalography monitoring for early prediction of neurological outcome in postanoxic patients after cardiac arrest: a prospective cohort study. Crit Care Med 2012;40(10):2867-75.

16. Spalletti M, Carrai R, Scarpino M, et al. Single electroencephalographic patterns as specific and time-dependent indicators of good and poor outcome after cardiac arrest. Clin Neurophysiol 2016;127(7):2610-7.

17. Forgacs PB, Devinsky O, Schiff ND. Independent functional outcomes after prolonged coma following cardiac arrest: a mechanistic hypothesis. Ann Neurol 2020;87(4):618-632.

18. Hofmeijer J, Tjepkema-Cloostermans MC, van Putten MJ. Burst-suppression with identical bursts: a distinct EEG pattern with poor outcome in postanoxic coma. Clin Neurophysiol 2014;125(5):947-54.

19. Barbella, G, Novy J, Marques-Vidal P, et al. Prognostic role of EEG identical bursts in patients after cardiac arrest: Multimodal correlation. Resuscitation 2020;148:140-144.

20. Chemali J, Chine S, Purdon PL, et al. Burst suppression probability algorithms: state-space methods for tracking EEG burst suppression. J Neural Eng 2013;10(5):056017.

21. Fleischmann A, Pilge S, Kiel T, et al. Substance-specific differences in human electroencephalographic burst suppression patterns. Front Hum Neurosci 2018;12:368.

22. Liang $Z$, Wang $Y$, Sun $X$, et al. EEG entropy measures in anesthesia. Front Comput Neurosci 2015;9:16.

23. Tobias JD. Bispectral index monitoring documents burst suppression during pentobarbital coma. J Intensive Care Med 2008;23(4):258-62.

24. Kälviäinen R, Eriksson K, Parviainen I. Refractory generalised convulsive status epilepticus : a guide to treatment. CNS Drugs 2005;19(9):759-68.

25. Van Ness PC. Pentobarbital and EEG burst suppression in treatment of status epilepticus refractory to benzodiazepines and phenytoin. Epilepsia 1990;31(1):61-7.

26. Kälviäinen R, Eriksson K, Parviainen I. Refractory generalised convulsive status epilepticus. CNS Drugs 2005;19(9): 759-768.

27. Wennberg R, Quesney F, Olivier A, et al. Induction of burstsuppression and activation of epileptiform activity after 
methohexital and selective amygdalo-hippocampectomy. Electroencephalogr Clin Neurophysiol 1997;102(5):443-51.

28. Kassell NF, Hitchon PW, Gerk MK, et al. Alterations in cerebral blood flow, oxygen metabolism, and electrical activity produced by high dose sodium thiopental. Neurosurgery 1980;7(6):598-603.

29. Shorvon S, Ferlisi M. The treatment of super-refractory status epilepticus: a critical review of available therapies and a clinical treatment protocol. Brain 2011;134(10):2802-2818.

30. de Heer IJ, Bouman SJM, Weber F. Electroencephalographic (EEG) density spectral array monitoring in children during sevoflurane anaesthesia: a prospective observational study. Anaesthesia 2019;74(1):45-50.

31. Dworacek B, De Vlieger M. Absence of electroencephalographic excitation pattern under isoflurane anesthesia. Acta Anaesthesiol Belg 1984;35(3):211-7.

32. Parviainen I, Kalviainen R, Ruokonen E. Propofol and barbiturates for the anesthesia of refractory convulsive status epilepticus: pros and cons. Neurol Res 2007;29(7):667-71.

33. Meierkord H, Boon $P$, Engelsen $B$, et al. EFNS guideline on the management of status epilepticus in adults. Eur J Neurol 2010;17(3):348-55. 